\title{
Reaction time as a function of fixed vs. variable foreperiod in the squirrel monkey
}

Robert W. Reymolds

UNIVERSITY OF CALIFORNIA, SANTA BARBARA

\begin{abstract}
A squirrel monkey was trained to press and hold down a lever in the presence of a blue light. Subsequent release of the lever on appearance of a white circle was reinforced with a food pellet. The monkey was tested under two different foreperiod conditions: (1) the white circle appeared at a variable period from 0-5 sec. following the lever press, and (2) the white circle appeared at a fixed 2 sec. interval following the lever press. The reaction time in the sessions with fixed foreperiod was consistently longer than the reaction time with variable foreperiod.
\end{abstract}

\section{Problem}

Reaction time (RT) or response latency is one of the most extensively studied variables in experimental psychology. This work, however, has been confined almost exclusively to human subjects (Teichner, 1954; Woodworth and Schlosberg, 1954). Recently, Stebbins and Lanson (1961) described a procedure for the measurement of RT in the rat. Stebbins and Reynolds (1964) used a modification of this procedure to study changes in RT following discrimination training in the pig-tail monkey. The present paper presents some data on the effect of fixed versus variable foreperiod on RT in the squirrel monkey.

\section{Method}

The single $\mathrm{S}$ was a healthy, adult male squirrel monkey (Saimiri sciureus).

Testing was conducted in a Lehigh Valley Electronics Model 1417 squirrel monkey test chamber equipped with a pellet feeder and a Grason Stadler E5704B multiple stimulus projector unit. The response lever was located $61 / 2$ in above the floor. A blue foreperiod light was located $11 / 2$ in below the lever, and the stimulus light, a white 1 in disk displayed on the stimulus projector, was located $21 / 2$ in above the lever. In addition to the noise from the ventilating fan, white noise at -15 db from a Grason Stadler noise generator was fed into the box to mask any sounds from outside the box.

Preliminary training was conducted as described by Stebbins and Reynolds (1964). S had been trained not to press the lever until the blue light was turned on. This light was programmed to come on $30 \mathrm{sec}$. after the last release of the lever ( $\mathrm{drl} 30 \mathrm{sec}$.$) . \mathrm{S}$ then had to press and hold the lever down until the white disk appeared. Release of the lever then yielded a $97 \mathrm{mg}$ peanut-flavored food pellet (P. J. Noyes Co.). Any deviation from this procedure turned off both lights for another $30 \mathrm{sec}$. with no food reward. The time between the lever press and the appearance of the white disk was considered the foreperiod. The time between the appearance of the white disk and the release of the lever was considered the reaction time. $\mathrm{S}$ was trained and tested under 22 hours food deprivation and was tested every day, seven days a week. Prior to the period for which the data are

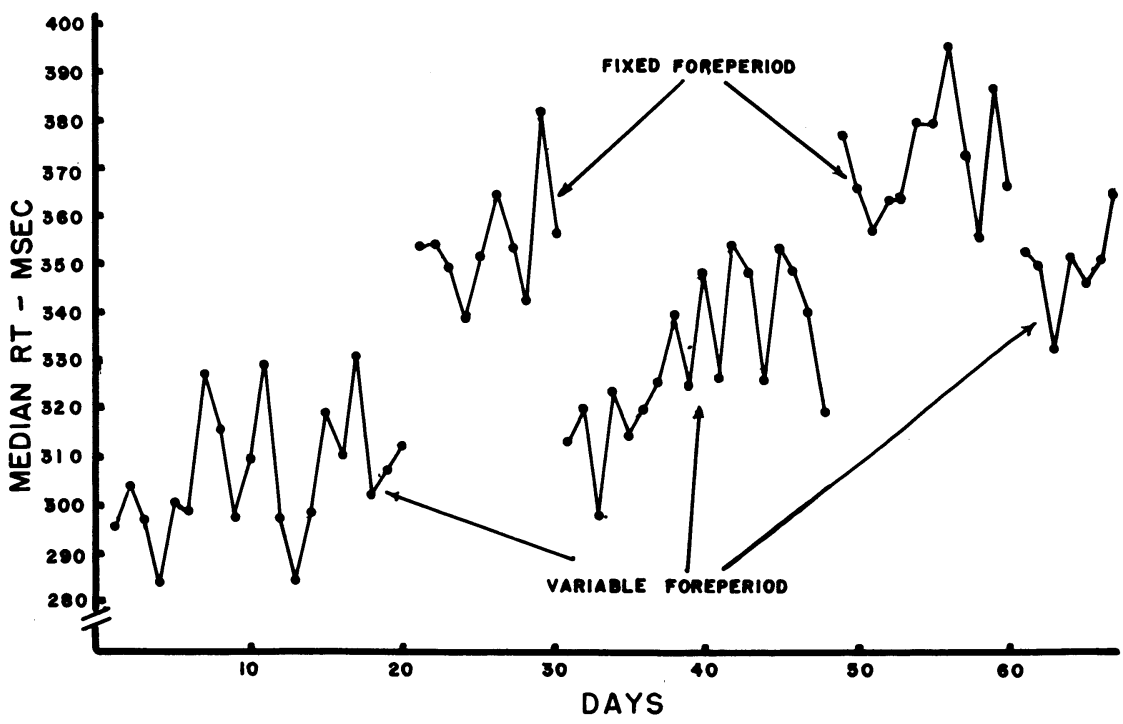

Fig. 1. The influence of type of foreperiod on median reaction time. 
presented $\mathrm{S}$ had been trained for over four months in the box. S was given 60 reinforced trials each day, followed by one hour ad lib feeding in his home cage. At the time covered by this paper, $\mathrm{S}$ was averaging less than one anticipatory response per day.

During the preliminary training and for the first 20 days shown in Fig. 1 the foreperiod was randomly variable from zero to five sec. That is, the white disk could appear at any time from zero to five sec. following the lever press. For the next ten days the program was changed so that the white disk always appeared exactly two sec. after the lever press. The variable foreperiod was then reintroduced for 15 days followed by another 12 days on a fixed foreperiod. The testing on this program was concluded with seven days on a variable foreperiod.

\section{Results}

As can be seen in Fig. 1, the change from a variable to a fixed foreperiod produced in both instances an immediate upward shift in median foreperiod of approximately $30 \mathrm{msec}$. The change from fixed to variable foreperiod produced an immediate downward shift. These effects are quite apparent in spite of the long term upward drift. Analysis of the data for two of the variable foreperiod sessions showed no significant correlation between foreperiod duration and RT. The semi-interquartile range averaged about $28 \mathrm{msec}$. under the fixed and 43 msec. under the variable foreperiod situations. This was a significant difference.

\section{Diseussion}

These data clearly demonstrate a shift in RT as a function of whether there is a fixed or a variable foreperiod. This shift, however, is in the opposite direction to that anticipated on the basis of reaction time studies in the human (Klemmer, 1956). It should be recalled that this animal had been given daily training and testing for over five months, a period much longer than that normally obtainable with human subjects. This may in part account for the difference in results. It is also possible that the uncertainty in the variable foreperiod situation maintains the animal in a higher state of arousal than is the case with the fixed foreperiod.

\section{References}

KLEMMER, E. T. Time uncertainty in simple reaction time. J. exp. Psychol., 1956, 51, 179-184.

STEBBINS, W. C., \& LANSON, R. N. A technique for measuring the latency of a discriminative operant. J. exp. Anal. Beh., 1961, 4, 149-155.

STEBBINS, W. C., \& REYNOLDS, R. W. Changes in response latency following discrimination training in the monkey. J.exp. Anal. Beh., 1964. In press. TEICHNER, W. H. Recent studies of simple reaction time. Psychol. Bull., 1954, 51, 128-149.

WOODWORTH, R. S., \& SCHLOSBERG, H. Experimental psychology. New York: Henry Holt, 1954.

\section{Acknowledgment}

Supported by University of California, Santa Barbara, Faculty Research Grant No. 144. 